\title{
Youth and the Study of Foreign Language: An Investigation of Attitudes
}

\author{
Kristin Hull Cortés \\ University of California, Berkeley
}

\begin{abstract}
This study was undertaken to assess the attitudes of elementary and middle school students toward foreign language (FL) study. A questionnaire, designed to measure student attitudes toward FL study and perceived parental support, was administered to 209 youth in grades three through eight, in two different school populations within the San Francisco Bay Area. The results of $\mathrm{t}$-tests show that students with home languages other than English demonstrated more positive attitudes toward FL and a higher degree of perceived parental support for their FL program than did students whose home language was English. There were no gender differences found on the total attitude score. However, a difference between the two school populations emerged, with students at School 1 scoring significantly higher on the attitude scale and reporting more parent support than students at School 2. The implications of the study are discussed and suggestions for future research are provided.
\end{abstract}

\section{Background}

Because language is a social event, and because an individual is profoundly shaped by the language he or she speaks, social considerations — such as the setting in which we learn language - are instrumental in explaining how people come to acquire a new language. According to Bialystok and Hakuta (1994), we express our response to these social considerations in the attitudes that we form toward the foreign language (FL) and in the extent to which we are motivated to learn a second language (L2).

Attitudes, in relation to FL learning, have been a popular subject of research in the past four decades, as attitudes are "both central to the understanding of human behavior and are capable of explication and measurement" (Baker, 1992, p. 20). Over the years, several definitions have been given to the term attitude. Its root meaning (derived from the Latin word 'aptus') is 'aptitude for action,' or having a tendency towards certain actions. Gardner and Lambert (1959), among the first language researchers to partake in such study, defined attitudes as major integrative forces in the development of personality that give consistency to an individual's behavior. As such, "our attitudes and motivation reflect how we view a situation and how much we would like to be a part of it" (Bialystok \& Hakuta, 1994, p. 34). In L2 research, "attitudes are a convenient and efficient way of explaining consistent patterns in behavior" (Baker, 1992, p. 11).

As is commonly known in the L2 field, Gardner and Lambert (1959; 1972) found that motivations to learn an L2 could be divided into two distinct categories. The first, instrumental motivation, focuses on an end goal. This type of motivation has been associated with practical benefits such as economic advances and personal achievement (e.g., graduation requirements, getting a job, earning more money, etc.). The second category, namely integrative motivation, drives the student to study an L2 to learn more about culture, to meet new people, or to become a

Kristin Hull Cortés is a PhD candidate at the University of California, Berkeley, Berkeley, California. 
part of the target language community. While instrumental and integrative motivations have different definitions, they are "not necessarily opposites or alternatives. Both are capable of existing within the same individual" (Baker, 1992, p. 35), and are by no means exclusive (Ely, 1986a); for any individual learner in Gardner and Lambert's studies, "there was extensive overlap of these two descriptions" (Bialystok \& Hakuta, 1994, p. 139). Much of the literature has depicted integrative motivation as key in acquiring an L2 (see, e.g., Gardner \& Lambert, 1959; Svanes, 1988). However, Gardner and MacIntyre (1991) found that both types of motivation facilitated learning. "The major thrust of research using integrative and instrumental attitudes has been in their role in L2 acquisition and achievement" (Baker 1992, p. 31). ${ }^{1}$

Additional research has shown that a correlation exists between the student's attitude toward the L2 and achievement in the L2 (Gardner \& MacIntyre, 1993). For example, Lambert (1974), in his seminal study, found both motivation for learning a language and attitude toward the target culture to be important factors in effective learning. According to Bialystok and Hakuta (1994), motivational factors "can create a more positive context in which language learning is likely to flourish" (p. 140). Gardner (1985) reviews relevant studies conducted in Canada and the United States, and discusses various issues and problems associated with language attitude research. He concludes that, in all of the studies, "The results clearly indicate a particular pattern of attitudinal-motivational components facilitated L2 acquisition" (p. 143). In fact, Gardner et al. (1987) found that "language attitudes are seen to 'cause' motivation" (p. 42) and that "motivation is shown to be a causal factor in determining L2 achievement and 'use' of the language" (p. 42). In other words, "Attitudes and motivations are important because they determine the extent to which the individuals will actively involve themselves in learning the language" (Gardner, 1985, p. 56).

Since the initial research by Gardner and Lambert, a variety of studies have examined aspects of attitudes and motivation in language learning. For example, student interest in and enrollment in FL classes was found to be influenced by the attitudes and opinions of students' family members and peers (Speiller, 1988; Zamir, 1981). Gardner (1985) also found that, for young learners, parental involvement in and attitudes toward language learning are two important factors in L2 development.

Another variable in attitudes toward language study, which has become popular among researchers, is that of gender differences. In a study of Japanese children learning English as an L2, it was found that girls had higher scores in both attitudinal and motivational variables than did boys (Koizumi, 1993). Similarly, Pritchard (1987) found, in an Irish study, that boys generally had less favorable attitudes toward FL learning than did girls. These findings correspond with widely held beliefs that "languages are a 'girls' subject" (Pritchard, 1987, p. 65) and that girls have more aptitude for FL learning than do boys. Sung and Padilla (1998) also found that female students reported greater motivation for FL study than did their male counterparts. However, in a Chicago study of elementary students' attitudes toward Hebrew, Ravid (1987) found no difference between boys' and girls' mean attitude scores.

Experience in the FL classroom, whether positive or negative, is yet another factor that has been shown to affect attitudes toward language learning (Glisan, 1987; Koizumi 1993). Travel or exposure to native language speakers has been associated with positive attitudes in FL students (Gardner \& Smythe, 1977). For example, Lee (1986) found that "higher proportions of pupils [studying French] who had visited France than those who had not, thought French was useful, enjoyable, and easy and wanted contact with the French community" (p. 73). Other variables found to affect attitudes toward FL include reactions to teaching methods and classroom activities, as well as student rapport with FL teachers and peers (Massey, 1994). In research where opinions of students regarding FL curriculum and content have been solicited, the results have revealed that students prefer more emphasis on speaking and less on formal grammar (see Glisan, 1987).

The degree of relevance that students see an FL having in their daily lives is also an important factor. Massey (1994) found that the role a language plays in the students' lives outside the FL classroom can be a significant influence on how involved they become in the learning process. Students in Massey's study were also greatly affected by the degree of enjoyment and the level of success they had experienced throughout their FL study. Similarly, Gardner et al. (1979) found that the sociocultural background of the student plays a major role in the development of attitudes toward FL learning. According to Edelsky (1991), other important factors in encouraging language learning are school policy and perceived status of the L2.

Student surveys have revealed both positive and negative attitudes toward FL study (see Glisan, 1987, and Roberts, 1992). However, the most frequent finding in the literature is the overwhelming support and interest on the part of students for FL study (Morello, 1988; Rhodes et al., 1989; Roberts, 1992). Of great relevance here is that students with more positive attitudes are more likely to participate in class and to be active learners (Gardner et al., 1976; Mantle-Bromley, 1995).

Attitudes toward FL have been explored by many researchers, but the majority of the studies on attitudes toward L2 learning has taken place outside the United States and has been conducted with predominantly college and high school age subjects. Though FLES programs 
(Foreign Language in the Elementary School) are proliferating in the United States, research on the attitudes of American youth has been virtually neglected. Several studies address students' abilities or performance in FL (see, e.g., Koizumi, 1993; Zamir, 1981), but few focus primarily on younger students' attitudes toward FL.

It is apparent, however, from the above-mentioned studies that the relationship between student attitudes and FL learning is complex and that there are many factors that affect the outcomes of this relationship. Some of these factors will be investigated in the present study.

This study explores the attitudes of younger students toward the beginning of their FL study, as attitudes that develop in these students' FLES programs may influence their future decisions regarding FL study. The present research reports data obtained from students ranging from third through eighth grades in two elementary schools where FL is taught. The purpose of this investigation was to test the following hypotheses:

1. Given the findings of Pritchard (1987) and Koizumi (1993), girls will demonstrate more positive attitudes toward FL study than will boys.

2. In accordance with the findings of Sung and Padilla (1998) and Gardner (1985), those students whose home languages include languages other than English will also demonstrate more positive attitudes toward learning a second language.

3. As found by Zamir (1981) and Gardner (1985), informants who perceive their parents as showing a high level of involvement in their FL study will demonstrate more positive attitudes toward FL learning than those students who perceive their parents as showing little interest in their FL program.

\section{Methods}

\section{Sample}

This study directs its attention to English-speaking elementary students enrolled in FL classes. The research was conducted at two different private schools in the San Francisco Bay Area. At the time of the research, few FLES programs could be found in area public schools. The two schools were chosen because both had similar FLES programs operating at each site, and the schools were similar in size, being kindergarten through eighth grade facilities.

The sample was comprised of 209 elementary students, of whom 100 were girls and 109 were boys. Ninetyone students were from School 1 and 118 students were from School 2. Students in grades three through eight participated in the study, as a third grade reading level was necessary to understand the questionnaire. All informants had been previously, or were presently, enrolled in some form of FL study, as required by each elementary school.
The programs at the two schools were similar in that students had an FL teacher come into their regular classrooms approximately twice a week for approximately 40 minutes each session. Eighty-three percent of the students were concurrently enrolled in Spanish FLES programs, 10\% were studying French, and 6\% were not enrolled in any FL class at the time of the study. ${ }^{2}$

English is the dominant language in both cities where the study took place. However, Spanish, among other languages, is commonly heard in the two communities (more so in community 1 than 2). Spanish radio and television (as well as Chinese and other languages) are also prevalent. The majority of the youth at School 2 are from middle class backgrounds, with some from the upper middle class and others from less affluent families. School 1 is made up of students who come from families of middle to lower middle class incomes. School 1 is located in a very ethnically and linguistically diverse section of a major West Coast city, whereas at School 2, located in an East Bay city, there is less diversity. Both school populations are comprised of many ethnic groups, with European-American, Hispanic, African-American, and Asian being the predominant ethnicities represented. In both schools, the majority of the students (65\%) are native English speakers. However, there is a significant number of students at both schools who are bilingual, whose parents' native language is not standard English, and who speak languages other than English at home.

\section{Instruments}

Students' attitudes were measured using an attitudes questionnaire. A preliminary pilot study was conducted to collect students' ideas, thoughts, and opinions about FL study. Interviews and focus group discussions were carried out in each of the two schools. Student responses were analyzed to determine if students' attitudes appeared to fall into general categories. The responses of the students were then used to create a four-part questionnaire. Rather than serve as a mold to which student perceptions must conform, each category of the questionnaire directly mirrored opinions found among the students.

The questionnaire consisted of 33 Likert-scale items with responses of "strongly agree," "agree," "disagree," and "strongly disagree" (see Appendix A). Part 1 of the questionnaire contained 8 items; four of these measured instrumental motivations for studying an FL (e.g., access to media, jobs, knowledge, and intelligence), and four were designed to measure integrative motivation (e.g., access to people and cultural groups). Part 2 of the questionnaire contained 13 items, five measuring instrumental motivations such as school requirements and advancement, parental demands, practical uses, and earning money. The remainder of the items in Part 2 measured integrative 
motives for the study of FL including travel, family heritage, enjoyment, friends, and integration into the community. Part 3 of the instrument comprised five items designed to assess student perceptions of parental attitudes toward FL study. Students were asked to indicate to what degree parents encouraged them to study FL, helped with homework, felt that the student should spend more time on the FL, should continue to study the FL, and were interested in the FL class.

In addition, the students were asked to rate how well they spoke Spanish and how well they thought they were doing in their FL class. This final section, consisting of 7 items, was intended to measure the degree to which students felt that learning an FL was important. Care was taken to randomly disperse positively and negatively worded statements, to encourage active and mindful responses.

In addition to the items constituting the major source of data for this study, other biographical data was obtained. The following information was available: students' age, grade level, and gender. Students were also asked to indi-

Table 1

ITEMS OF STRONG AGREEMENT AND STRONG DISAGREEMENT

\begin{tabular}{|c|c|c|c|}
\hline Items & Mean & Variance & Standard Deviation \\
\hline $\begin{array}{l}\text { 1. Knowing another language will } \\
\text { allow me to meet and talk with a lot of different people }\end{array}$ & 3.38 & .47 & .69 \\
\hline $\begin{array}{l}\text { 2. Knowing another language will allow me to be } \\
\text { more comfortable with people that speak that language }\end{array}$ & 3.09 & .51 & .74 \\
\hline 3. Knowing a foreign language will help me in high school & 3.18 & .61 & .78 \\
\hline 4. My parents think I should continue to study Spanish & 3.09 & 2.44 & 1.56 \\
\hline 5. It is important to speak English and another language & 3.18 & .68 & .82 \\
\hline 6. Schools should just teach in English & 1.73 & .818 & .904 \\
\hline 7. People only need to know one language & 1.78 & .80 & .895 \\
\hline
\end{tabular}

Table 2

T-TEST OUTCOMES FOR INTEGRATIVE AND INSTRUMENTAL MOTIVATION SCALES BY HOME LANGUAGE AND GENDER

\begin{tabular}{lcccc}
\hline & \multicolumn{2}{c}{ Home Language } & \multicolumn{2}{c}{ Gender } \\
& English & Others & Boys & Girls \\
\hline Integrative Mean Scores & 12.85 & $13.95^{*}$ & 12.97 & 13.44 \\
\hline Instrumental Mean Scores & 16.33 & 17.15 & 16.53 & 16.66 \\
\hline${ }^{*} \mathrm{p}>.01$ & & & & \\
& & & \\
\end{tabular}

\section{Table 3}

TOTAL SCORES COMPARED BY

STUDENTS' HOME LANGUAGE AT SCHOOLS 1 AND 2

\begin{tabular}{lcc}
\hline & \multicolumn{2}{c}{ Home Language } \\
& English & Other \\
\hline School 1 & 73.97 & 78.75 \\
\hline School 2 & 67.56 & 74.92 \\
& & \\
\hline
\end{tabular}

\section{Table 4}

PERCEIVED PARENTAL INVOLVEMENT VS. STUDENTS' HOME LANGUAGE AT SCHOOLS 1 AND 2

\begin{tabular}{lcc}
\hline & \multicolumn{2}{c}{ Home Language } \\
& English & Other \\
\hline School 1 & 14.443 & 16.139 \\
\hline School 2 & 12.875 & 13.760 \\
\hline
\end{tabular}


cate their first language, languages spoken at home, and knowledge of other languages. Finally, students were asked what they wanted to do when they grew up and whether they knew anyone from a culture different from their own.

A Factor Analysis was calculated using the 33 Likertstyle questionnaire items. One factor, which included 26 items, emerged. These 26 items were then totaled to provide an "Attitude toward FL" Scale. Using this attitude scale, an attitude score ranging from 26 to 104 was computed for each of the 209 informants.

Despite the emergence of a single factor (which may prove that these distinctions are irrelevant), several items on the attitude scale that historically have been recognized as either instrumental or integrative motivations (see Gardner \& Lambert, 1972) were separated into sets. Six items ("meet and talk to different people," "be comfortable with people that speak that language," "participate in activities of other cultural groups," "have friends that speak Spanish and I want to be able to talk to them," "relatives," and "will help me be accepted in my community") were grouped together to form an "Integrative Motivation Set." Six different items ("read literature," "knowing another language will make me more knowledgeable," "helpful in getting a job," "people will think I am smarter," "will help me in high school," and "will help me earn lots of money") were grouped together to form an "Instrumental Motivation Set." Potential scores for both of these sets ranged from 6 to 24 .

\section{Administration Procedures}

The questionnaire was administered during regular class periods. The youth were recruited on a voluntary basis, and most were enthusiastic about participating in the project. Permission was obtained from the students and from their parents, teachers, and principals. The students were instructed not to write their names on the questionnaires. They were assured that all responses would remain anonymous, that no portion of their responses would influence grades in any of their classes, and that there were no right or wrong answers.

The questionnaire took approximately 15 to 30 minutes to complete. The nature and purpose of the study were explained to the students. The students were asked to provide as true an answer as they were able for each statement. To insure consistency, there was a single questionnaire administrator in every classroom who was well known to the majority of the students and was available to clarify any questions. Questionnaires were completed by students in grades $3,4,7$, and 8 at School 1 , and by students in grades 3, 4, 5, and 8 at School 2. The completed questionnaires were then scored, and the information was coded to facilitate computer analysis.

\section{Results}

The results of this study confirmed several hypotheses but did not lend support to others. In general, informants scored high on this attitude measure (scores ranged from 34 to 104 ; mean score $=72.69$; variance $=169.39$; standard deviation $=13.02$ ). These high scores signify that students had very positive attitudes toward learning an FL and lend

Figure 1

TOTAL MEAN FL ATTITUDE SCORE BY HOME LANGUAGE BACKGROUND BY SCHOOL

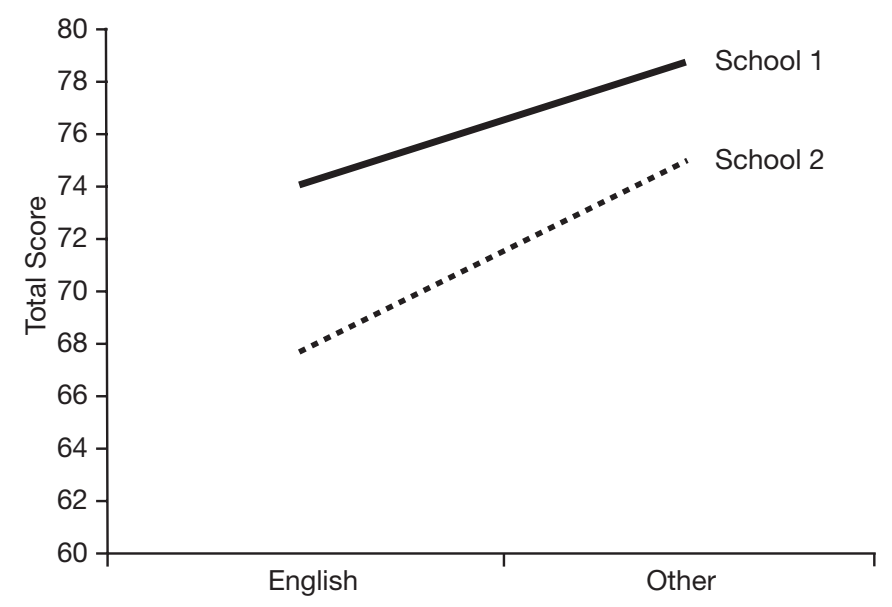

\section{Figure 2}

PERCEIVED PARENTAL INTEREST BY HOME LANGUAGE BY SCHOOL

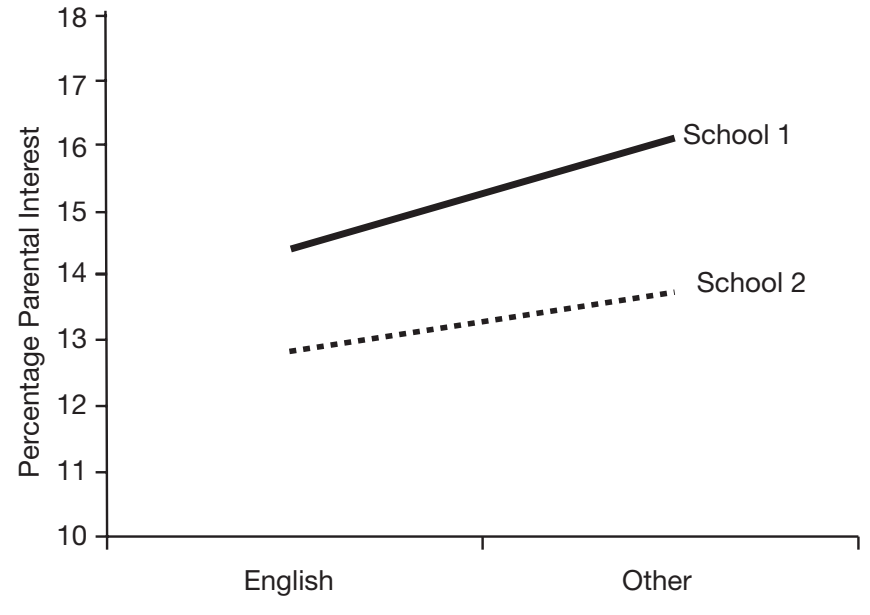


support to the findings of Rhodes et al. (1989) and Roberts (1992). The five items with which students most strongly agreed are listed in Table 1. Two items of strong disagreement were "Schools should just teach in English" and "People only need to know one language" (see Table 1).

\section{Gender}

A $t$-test was computed between questionnaire results of male and female students (for other studies using t-tests in the analysis of FL attitudes, see, e.g., Ravid, 1987, or Samimy \& Tabuse, 1992). Although the mean total score for females was somewhat higher than the male score $(F=$ 74.01, $m=71.63)$, there was no significant gender effect found $(t=-0.765 ; d f=157.3 ; p<.45)$.

Separate $t$-tests were computed for the 32 items on the attitude scale between girls and boys. For 28 of the items, no significant difference was found. Four items were shown to be significantly different when t-tests were computed. For
Part 2, item 3, "Spanish is my heritage language," few males or females agreed that Spanish was their heritage language, but boys did score higher than girls (mean scores: $\mathrm{m}=1.94$, $F=1.55)$, on a Likert scale ranging from 1 to $4(t=2.47 ; d f$ $=187.9 ; p<.014)$. These scores reflect the actual heritage of the students. In Part 2, item 8, "I think that studying another language is fun," females scored significantly higher than males (mean scores: $m=2.51, F=3.12 ; t=-4.365 ; d f=$ $202.4 ; p<.000)$. Similarly, girls scored higher than did boys on item 9, "I thought that taking Spanish classes would be an interesting thing to do." On this item, neither gender strongly agreed or disagreed; however, girls indicated more positive answers than did boys $(m=2.43, F=2.80 ; t=$ $-2.922 ; d f=200.9 ; p<.004)$. The last item that produced a gender difference was "To live in the USA you only need to speak English," which appeared in the last section of the questionnaire. On this item, both genders showed disagreement. Girls demonstrated a high level of disagreement $(F=$

\section{Table 5}

OUTCOMES FOR T-TESTS BY GENDER AND GRADE LEVEL

\begin{tabular}{|c|c|c|c|c|}
\hline \multirow[t]{2}{*}{ Items } & \multicolumn{2}{|c|}{ Gender } & \multicolumn{2}{|c|}{ Grade Level } \\
\hline & Male & Female & 3 and 4 & 7 and 8 \\
\hline Talk to different people & 3.34 & 3.42 & 3.26 & $3.57 * *$ \\
\hline Participate in other cultures & 2.64 & 2.77 & 2.57 & $2.86^{*}$ \\
\hline More knowledgeable & 3.16 & 2.98 & 2.89 & $3.34 * * *$ \\
\hline Spanish is my heritage language & 1.94 & $1.55^{*}$ & 1.55 & $2.06^{* *}$ \\
\hline I want to travel and use Spanish & 2.79 & 2.90 & 2.46 & $3.38^{* * *}$ \\
\hline Can use Spanish around town & 2.42 & 2.33 & 2.08 & $2.80 * * *$ \\
\hline Studying another language is fun & 2.51 & $3.12 * * *$ & 3.03 & $2.70^{*}$ \\
\hline Taking FL is interesting & 2.43 & $2.80 * *$ & 2.68 & 2.70 \\
\hline Community & 1.98 & 2.08 & 2.19 & $1.79 * *$ \\
\hline Parents encourage & 2.88 & 2.76 & 2.52 & $3.29 * * *$ \\
\hline Help with homework & 2.76 & 2.55 & 2.35 & $2.85^{*}$ \\
\hline Parents want me to study more & 2.79 & 2.57 & 2.38 & $2.99 * *$ \\
\hline Parents want me to continue & 3.12 & 3.05 & 2.76 & $3.57 * * *$ \\
\hline FL is creative & 2.88 & 3.02 & 2.80 & $3.18^{* *}$ \\
\hline Job & 3.15 & 2.89 & 2.77 & $3.30 *$ \\
\hline Schools should just teach English (1) & 1.84 & 1.62 & 1.82 & $1.56^{*}$ \\
\hline English is the only language needed in the USA & 2.76 & $3.24 * * *$ & 2.86 & 2.98 \\
\hline Schools should just teach English (2) & 3.18 & 3.40 & 3.46 & $3.21^{*}$ \\
\hline $\begin{array}{l}{ }^{*} p<.05 \\
{ }^{* *} p>.01 \\
{ }^{* * *} p>.001\end{array}$ & & & & \\
\hline
\end{tabular}


1.79), while the boys disagreed only slightly $(m=2.25), t=$ 3.463; $d f=202 ; p<.000$ (see Table 5).

In a $t$-test computed between genders for integrative motivation, girls scored somewhat, but insignificantly, higher than boys (mean scores: $F=13.47, m=12.97$ ). On the instrumental variable, there were no gender differences found (mean scores: $F=16.66, m=16.51$ ). Both genders scored higher on Instrumental motivation than on the Integrative variable (see Table 2).

\section{Home Language}

Separate $t$-tests were computed for the 32 items on the attitude scale between home language 1 (students who spoke only English at home) and home language 2 (students who indicated speaking any non-English language at home). As predicted, those students whose home language included languages other than English scored higher, demonstrating more positive attitudes, on every item on the attitude scale. Those students who spoke only English at home $(n=111)$ had an average total score of 71.14 , whereas those students whose home language included languages other than English $(n=53)$ shared a mean score of $75.93(t=-2.41$; $d f=124.8 ; p<.017$ ) (see Figure 1). Students at both schools who spoke languages other than English at home demonstrated higher attitude scores than did those students whose reported home language was English (see Table 3).

Items for which there was significance at the .001 level include: "Spanish is my heritage language" $(t=-3.568$; $d f$ $=119.8 ; p<.001)$ and "I have relatives who speak Spanish and I want to be able to talk to them" ( $t=-3.408 ; d f=$ $122.7 ; p<.001)$. Items for which there was significance at the .05 level include "I want to travel to places where Spanish is spoken" $(t=-2.103 ; d f=136.2 ; p<.037)$, "I think that studying another language is fun" ( $t=-2.41$; $d f$ $=152.5 ; p<.017)$, "Speaking another language will help me earn lots of money when I am older" $(t=-2.215 ; d f=$ $132.8 ; p<.028)$, and "Knowing English plus another language can make a person more creative" $(t=-2.538 ; d f=$ $162.1 ; p<.012$ ) (see Table 6).

Two $t$-tests comparing Integrative and Instrumental variables were also computed between home language 1 (where only English was spoken) and home language 2 (where other languages in addition to English were used in

Table 6

T-TEST OUTCOMES FOR SIGNIFICANT ITEMS BY SCHOOL AND HOME LANGUAGE

\begin{tabular}{|c|c|c|c|c|}
\hline \multirow[t]{2}{*}{ Items } & \multicolumn{2}{|c|}{ School } & \multicolumn{2}{|c|}{ Home Language } \\
\hline & 1 & 2 & English & Others \\
\hline Knowledge & 3.22 & $2.95^{*}$ & 3.06 & 3.10 \\
\hline Have to & 2.20 & $2.95 * * *$ & 2.63 & 2.64 \\
\hline Parents & 2.38 & $2.69 *$ & 2.49 & 2.68 \\
\hline Heritage & 1.98 & $1.59 *$ & 1.55 & $2.17 * * *$ \\
\hline Travel & 3.18 & $2.59 * *$ & 2.69 & $3.15^{*}$ \\
\hline Town & 2.76 & $2.07 * * *$ & 2.34 & 2.43 \\
\hline Fun & 2.84 & 2.77 & 2.69 & $3.04 *$ \\
\hline Interest & 2.78 & $2.48^{*}$ & 2.58 & 2.67 \\
\hline Relative & 2.00 & 2.01 & 1.82 & $2.36^{* * *}$ \\
\hline Money & 2.00 & $2.26^{*}$ & 2.05 & $2.34^{*}$ \\
\hline Parents encourage & 3.10 & $2.61^{*}$ & 2.77 & 2.94 \\
\hline Continue & 3.47 & $2.79 * *$ & 3.06 & 3.14 \\
\hline Parental interest & 2.90 & $2.45^{*}$ & 2.58 & 2.78 \\
\hline Important to speak another language & 3.34 & $3.06^{*}$ & 3.12 & 3.32 \\
\hline FL is creative & 3.10 & $2.83^{*}$ & 2.84 & $3.15^{*}$ \\
\hline $\begin{array}{l}\mathrm{p}<.05^{*} \\
\mathrm{p}>.01^{* *} \\
\mathrm{p}>.001^{* * *}\end{array}$ & & & & \\
\hline
\end{tabular}


the home). Those students who reported speaking English at home scored lower on both measures (Integrative and Instrumental) than students whose home language included languages other than English. A Pearson Correlation was calculated for parent involvement and total score. The correlation was .776. Finally, a $t$-test was computed for parental involvement between home language 1 and home language 2. Mean scores are reported in Table 4 and displayed in Figure 2.

\section{Grade Level}

A $t$-test was computed comparing total attitude scores by grade level. Students in grades 3 and $4(n=69)$ had a mean score of 67.30 , whereas the average for seventh and eighth graders $(n=69)$ was $73.30(t=2.92 ; d f=121.4 ; p<.002)$.

Analysis of Variance was also used to examine grade level data (for other examples of ANOVA use in research concerning FL attitudes, see Gardner et al, 1989, or Svanes,

\section{Table 7}

TOTAL ATTITUDE SCORES BY SCHOOL AND GRADE LEVEL

\begin{tabular}{lcc}
\hline Grade & School 1 & School 2 \\
\hline 3 & 60.22 & 69.11 \\
\hline 4 & 70.38 & 73.96 \\
\hline 5 & & 70.09 \\
\hline 7 & 80.10 & \\
\hline 8 & 78.73 & 69.471 \\
\hline
\end{tabular}

\section{Figure 3}

TOTAL ATTITUDE SCORE BY GRADE BY SCHOOL

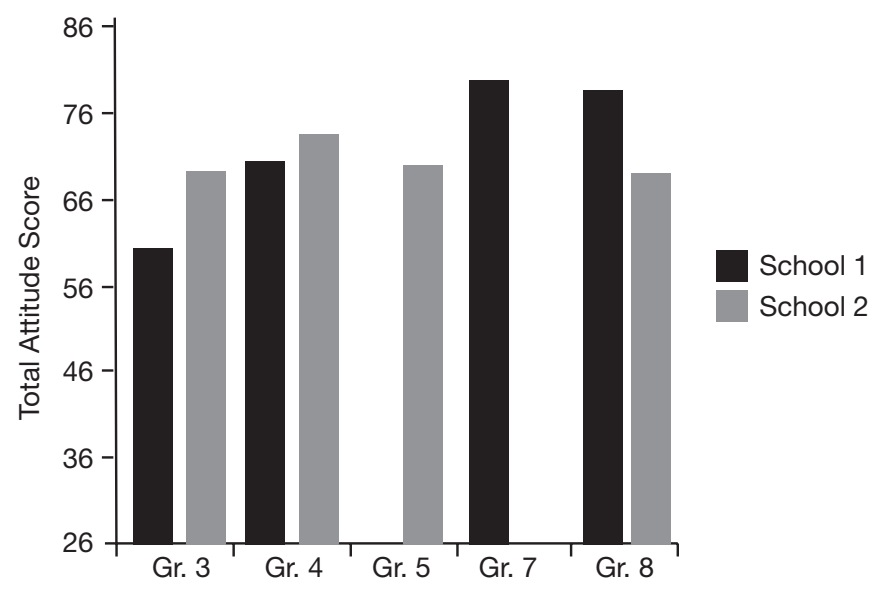

1988). The ANOVA table shows that the main effect for schools was not significant, but there was a significant effect for grade level $(F=15.44 ; d f=1,131 ; p<.000)$. Furthermore, the interaction was significant $(F=9.19 ; d f=$ $1.131 ; p<.003)$. Attitudes in School 1 generally increased by grade level, whereas attitudes decreased with grade level in School 2 (see Table 7 and Figure 3).

ANOVA was used to compute a $2 \times 2$ Analysis of Variance with students' home language and grade level as the main effects. The ANOVA table shows that the main effect for home language was not significant, but there was a significant effect for grade level $(F=5.06 ; d f=1,131 ; p<$ .022). The interaction was not significant (see Figure 4).

ANOVA was also used for gender and grade level. Again, the main effect for grade level was significant $(F=$ $7.12 ; d f=1,131 ; p<.000)$. There was no interaction.

\section{Schools}

Various $t$-tests were used to compare each item on the attitude scale by the two different schools. As predicted, the attitudes of the students at School 1 were more positive than those of the students at School 2 (mean scores: School $1=74.85$, School $2=70.82 ; t=1.931 ; d f=123.5 ; p<.048)$. On the first item in Part 2, "I am studying another language because I have to for school," the students at School 1 disagreed, while the students at School 2 agreed (mean scores: School $1=2.20$, School $2=2.95 ; t=-5.051 ; d f=168.3 ; p<$ $.001)$. The students at the second school also agreed with the item "I am studying another language because my parents wanted me to," whereas the students at the first school disagreed (mean scores: School $1=2.38$, School $2=2.69 ; t$ $=-2.315 ; d f=177.9 ; p<.02)$. School 1 students scored significantly higher on the following items: Knowledge, Heritage, Travel, Town, Interest, Parents encourage, Parents think I should continue, Parent Interest, Important to speak English and another Language, and Creative (see Table 6).

Two $t$-tests were also computed for Integrative and Instrumental motivations between the two different school populations, with no significant differences found. Both schools did score higher on instrumental motivation $(t=-0.343 ; d f=$ $182.9 ; p<0.732)$ than on the integrative scale $(t=$ $.103 ; d f=170.5 ; p<0.918)$.

\section{Discussion}

\section{Gender}

While there seems to exist a belief among Americans that girls have more positive attitudes toward FL than do boys, the data from this study do not support this belief. The gender results support those of Ravid (1987), who found - in a 
study of attitudes toward Hebrew - no significant differences in the mean attitude scores of American boys and girls, and contradict the findings of Koizumi (1993) and Pritchard (1987). The mean attitude scores of girls and boys in this study did not differ significantly. However, girls in this study found FL classes to be more fun and more interesting than did boys.

Though gender differences could have been mitigated by the home and school effects in this sample, this study's findings confirm those of a parallel quantitative study where, in interviews, boys indicated that learning a FL was "important, but boring," or "very boring." An eighth grade boy from School 2 stated that, "It would be cool to talk to other people, but I don't want to go through the whole process of learning it, 'cause it's boring" (Cortés, 2002). These results are important if we are to encourage and support both genders in L2 acquisition.

The findings point to future studies that examine what types of curricula are currently being used in FLES classrooms and help determine which of these approaches to language learning are appealing to both genders. Further research is also necessary to investigate whether parallel attitude scores occur predominantly at the elementary age level or whether these positive attitudes remain constant as girls and boys enter their teenage and adult years.

\section{Home Language}

A second result of this study was the emergence of a home language factor. Students who came from a household where a nondominant language is spoken invariably scored higher than students who spoke only English at home. This finding confirms the stated hypotheses and offers support to Massey (1994), who suggests that the role that a language plays in the students' lives outside the FL classroom can be a large influence on how involved the student becomes in the learning process. This result also lends support to Gardner (1979) and Zamir (1981), who found that the sociocultural background of the student plays a major role in the development of attitudes toward FL study. This finding has implications for FL teachers in terms of offering extra support or encouragement to students who do not come from bilingual homes.

Cortés (2002) also found that students demonstrated interest in studying a language that correlated with their family or ethnic heritage. For example, African American boys indicated the desire to study Swahili, and Chinese American boys were interested in Chinese. Future research

\section{Figure 4}

might investigate this home language factor as to whether children's positive attitudes toward FL study are correlated with exposure to different languages, or whether there are specific cultural or parental factors that influence students.

\section{School Site Difference}

There are several possible explanations for the school effect demonstrated by this study. The difference in attitudes between the two schools may be due to the difference in level of exposure to diversity. School 1, which demonstrated more positive attitudes, is located in a more ethnically and linguistically diverse neighborhood than is School 2. Such an explanation is plausible because exposure to native language speakers has been correlated with positive attitudes in FL students. The school attitude difference could also be attributed to differing levels of support for the FL programs. At School 1, the FL program and teachers were supported and well liked by the administration, the parents, and the students, but the FL program and teacher at School 2 did not receive similar support.

Recommendations for future research include constructing an index of school support for FL with data gathered from parents and staff members at each school. Use of such an instrument may provide a sense of what degree support for FL (or lack of it) within a school setting influences students' attitudes.

A third explanation for the difference in attitudes between the two school sites could be differences in FL teaching styles and practices. The FL teacher at School 1 used a very hands-on approach whereby students were involved in activities such as singing, puppet shows, and

TOTAL ATTITUDE SCORE BY GRADE BY SCHOOL

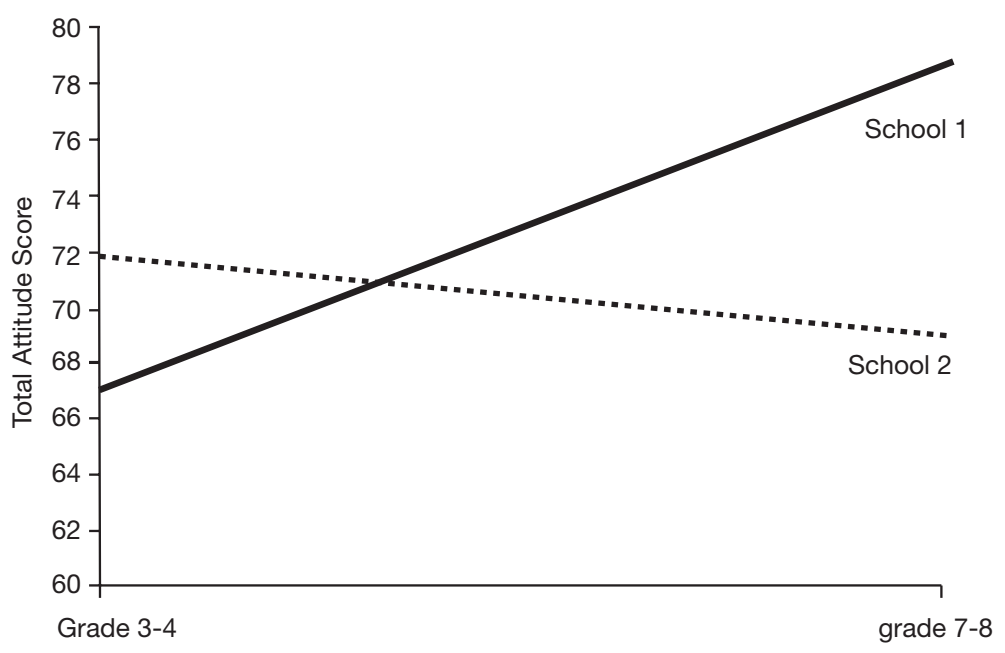


games, whereas the teacher at School 2 used a more traditional grammar-translation approach to teaching Spanish. She drilled the students on grammar points from worksheets and had frequent tests and quizzes. Through interviews and observation, the author found that upper-grade students at School 1 appeared more enthusiastic with regard to their FL classes than did those students at School 2 (2002). In fact, several students from School 2 expressed dissatisfaction with their Spanish teacher and felt that their FL experience would be enhanced with a new or different teacher.

In responses to interview questions, many students at both schools mentioned the teacher as a key variable in learning FL. Statements such as "FL is fun when the teacher teaches stuff in a new or exciting way," "If you have a good teacher, then it can be fun and educational," and "boring or interesting, it depends on how the teacher teaches" were common, indicating that the teacher plays an important role in formulating the students' attitudes and opinions regarding L2 learning. This finding aligns itself with that of Massey (1994), who found that teaching methods may contribute to students' attitudes toward FL. In fact, Smith and Massey (1987) found that students' attitudes toward learning a FL could be greatly affected by their teachers' expectations and the curricula used in the first few weeks of the course.

The school effect could be accounted for by one or a combination of all three of the above explanations. Future research is needed to further explore whether these kinds of factors affect students' attitudes toward FL.

The findings of this study provide information about students' attitudes and motivations in the FL classroom, as well as implications for language pedagogy and adult support for young FL learners. If we believe FL learning offers many benefits to society and the individual, then we need to consider the attitudes of students in the FL classroom. For example, understanding these attitudes may help FL educators retain learners long enough for them to reach high proficiency levels. And as we continue to see an increased need for bilingual members of the workforce, it will be crucial that we understand students' motivations for enrolling and continuing in FL programs. That is, to increase the number of persons capable of communicating effectively in languages other than English, we must orient our language instruction toward students' personal reasons for learning foreign languages.

\section{Acknowledgments}

I would like to thank Emily Spinelli and the anonymous reviewers for their careful reading of and constructive comments on earlier drafts of this paper. I would also like to express my appreciation to Amado Padilla and Guadalupe Valdés for their assistance in building the research design for this study, and to Paul Ammon and Eugene Garcia for helpful comments and suggestions on an earlier draft. I am also grateful to David Duran and Tomas Galguera for their technical assistance.

\section{Notes}

1. Since the work of Gardner and his associates, other L2 researchers have advanced different attitude and motivation models in addition to the instrumental and integrative models discussed here. See, for example, Dornyei 1994 and Noels 2001.

2. Both schools required participation in FL study for all grades with the exception of 7 th and 8th grade students at School 1. During the year of the study, 7th and 8th grade students at School 1 were offered, for the first time, the option of continuing the study of Spanish, switching to French, or discontinuing FL study altogether. Thus, though some students were currently studying French and several students were not presently studying any FL, they are included in the data sample, as all of these students had experience in the FLES program.

\section{References}

Baker, C. 1992. Attitudes and language. Avon, England. Multilingual Matters Ltd.

Bialystok, E., \& Hakuta, K. 1994. In other words. New York: Basic Books.

Cortés, K. H. (2002). Youth and the study of foreign language: A qualitative look at attitudes. Unpublished study.

Dornyei, Z. (1994). Motivation and motivating in the foreign language classroom. Modern Language Journal, 78, 273-84.

Edelsky, C. (1991).With literacy and justice for all. London: The Falmer Press.

Ely, C. M. (1986). Language learning motivation: A descriptive and casual analysis. Modern Language Journal, 70, 28-35.

Gardner, R. (1985). Social psychology and second language learning. London: Edward Arnold.

Gardner, R., \& Lambert, W. (1959). Motivational variables in second language acquisition. Canadian Journal of Psychology, 13, 266-72.

Gardner, R., \& Lambert, W. (1972). Attitudes and motivation in second-language learning. Rowley, MA: Newbury House Publishers.

Gardner, R., \& MacIntyre, P. (1993). A student's contributions to second language learning. Part 2: Affective variables. Language Learning, 26, 1-11.

Gardner, R., \& MacIntyre, P. (1991). An instrumental motivation in language study: Who says it isn't effective? Studies in Second Language Acquisition, 13,1, 57-72.

Gardner, R., \& Smythe, P. C. (1977). Intensive second language study: Effects of attitudes, motivation and French achievement. 
Language Learning, 27,2, 243-61.

Gardner, R. et al. (1976). Second language learning: A social psychological perspective. Canadian Modern Language Review, $32,2,4$.

Gardner, R. et al. (1979). Intensive second language study in a bicultural milieu: An investigation of attitudes, motivation and language proficiency. Language Learning, 29,2, 305-20.

Gardner, R. et al. (1987). Second language attrition. Journal of Language and Social Psychology, 6, 28-47.

Gardner, R. et al. (1989). Second language learning in an immersion programme. Journal of Language and Social Psychology, 8, 287-304.

Glisan, E. (1987). Beginning Spanish students. Hispania, 70, 381-94.

Koizumi, R. (1993). A longitudinal study of attitudes and motivation in learning English among Japanese seventh-grade students. Japanese Psychological Research, 35, 1-11.

Lambert, R. (1981). Language learning and utilization. ADFL Bulletin, 13, 7-11.

Lambert, R. (1974). Culture and language factors in learning and education. In F. E. Aboud \& R. D. Meade (Eds.), Cultural factors in learning and education. Washington, DC: Fifth Western Washington Symposium on Learning.

Lee, B. (1986). French is hard because it's a different language. British Journal of Language Teaching, 24, 71-6.

Mantle-Bromley, C. (1995). Positive attitudes and realistic beliefs: Links to proficiency. The Modern Language Journal, $79,3,372-86$.

Massey, A. (1986). Variations in attitudes and motivation of adolescent learners of French as a second language. The Canadian Modern Language Review, 42, 607-18.

Massey, A. (1994). Why choose French? Secondary school students' accounts of their decision to leave or enroll in the Ontario regular FSL programme. The Canadian Modern Language Review, 50, 714-35.

Morello, J. (1988). Attitudes of students of French toward required language study. Foreign Language Annals, 21, 435-42.
Noels, K. (2001). Learning Spanish as a second language: Learners' orientations and perceptions of their teachers' communication style. Language Learning, 51, 107-44.

Pritchard, R. (1987). Boys' and girls' attitudes towards French and German. Educational Research, 29, 65-71.

Ravid, R. (1987). The correlation of parents' and students' attitudes with Hebrew language achievement. Foreign Language Annals, 20, 421-25.

Rhodes, N., Thompson, L., \& Snow, M. A. (1989). A comparison of FLES and immersion programs: Final report. Washington, DC: Center for Language Education and Research, Center for Applied Linguistics.

Rivers, W. (1971). Foreign languages in a time of change. Paper presented at the University Foreign Language Articulation Conference, University of Illinois, Urbana, IL.

Roberts, L. (1992). Attitudes of entering university freshmen toward foreign language study. Modern Language Journal, 76.

Samimy, K. (1994). Teaching Japanese: Consideration of learners' affective variables. Theory into Practice, 33, 29-33.

Samimy, K., \& Tabuse, M. (1992). Affective variables and a less commonly taught language. Language Learning, 42, 377-98.

Smith, H. A., \& Massey, D. A. (1987). Students' attitudes toward French as a second language: Their stability and relationship to classroom behaviors. The Canadian Modern Language Review, 43,2, 314-36.

Speiller, J. (1988). Factors that influence high school students' decisions to continue or discontinue the study of French and Spanish after levels 2, 3, and 4. Foreign Language Annals, 21,6, 535-45.

Sung, H., \& Padilla, A. (1998). Student motivation, parental attitudes, and involvement in the learning of Asian languages in elementary and secondary schools. Modern Language Journal, 82, 205-16.

Svanes, B. (1988). Attitudes and 'cultural distance' in second language acquisition. Applied Linguistics, 9, 357-71.

Zamir, J. (1981). U.S. suburban middle class attitudes toward foreign language learning studies. Language Learning, 3, 42-77. 


\section{Appendix A.}

\section{Student Questionnaire}

Gender: Male Female School

Grade:

What is your ethnic background?

What languages do you speak?

Which languages are spoken in your home?

Have you studied any other languages besides Spanish? Yes No

If "No", skip down to "Do you have..."

If you answered "yes", please list the languages that you have studied:

Where did you learn these languages?

Do you have friends or do you know anyone from another culture? (please specify)

What would you like to do when you grow up?

\section{Part 1}

Please circle the number that indicates how well you agree with each of the statements below. 4 = strongly agree $\quad 3$ = agree $\quad 2$ = disagree $\quad 1=$ strongly disagree

Example:

"Studying another language is important because..."

(0) I will then be able to watch and understand different TV stations.

$$
4 \text { (strongly agree) } \quad 3 \text { (agree) } \quad 2 \text { (disagree) } \quad 1 \text { (strongly disagree) }
$$

"Studying another language is important because...."

(1) knowing another language will allow me to meet and talk with a lot of different people.

$$
\begin{array}{llll}
4 & 3 & 2 & 1
\end{array}
$$

(2) knowing another language will allow me to be more comfortable with people that speak that language.

$$
\begin{array}{llll}
4 & 3 & 2 & 1
\end{array}
$$

(3) if I know another language then I will be able to read literature (books, newspapers, stories) in that language.

$$
\begin{array}{llll}
4 & 3 & 2 & 1
\end{array}
$$

(4) I will be able to participate in the activities of other cultural groups.

$$
4 \quad 321
$$

(5) knowing another language makes me a more knowledgeable person. $\begin{array}{llll}4 & 3 & 2 & 1\end{array}$

(6) I think it will be helpful in getting a job.

$$
\begin{array}{llll}
4 & 3 & 2 & 1
\end{array}
$$

(7) other people will think I am smarter if I know another language.

$$
\begin{array}{llll}
4 & 3 & 2 & 1
\end{array}
$$

\section{Part 2}

"I am studying another language because...."

(1) I have to for school.

$$
\begin{array}{llll}
4 & 3 & 2 & 1
\end{array}
$$

(2) my parents wanted me to.

$$
\begin{array}{llll}
4 & 3 & 2 & 1
\end{array}
$$

(3) Spanish is my heritage language (the language of my family).

$$
\begin{array}{llll}
4 & 3 & 2 & 1
\end{array}
$$

(4) I want to travel to places where Spanish is spoken.

$\begin{array}{llll}4 & 3 & 2 & 1\end{array}$

If you do want to travel and use your foreign language, to which places would you like to go? 
(5) I can use Spanish in my neighborhood and around town.

$\begin{array}{llll}4 & 3 & 2 & 1\end{array}$

(6) I can use another language for practical reasons like ordering in a restaurant or at the store.

$\begin{array}{llll}4 & 3 & 2 & 1\end{array}$

(7) Knowing a foreign language will help me in high school.

$\begin{array}{llll}4 & 3 & 2 & 1\end{array}$

(8) I think that studying another language is fun.

$\begin{array}{llll}4 & 3 & 2 & 1\end{array}$

(9) I thought that taking Spanish classes would be an interesting thing to do. $\begin{array}{llll}4 & 3 & 2 & 1\end{array}$

(10) I have friends who speak Spanish and I want to be able to talk to them. $\begin{array}{llll}4 & 3 & 2 & 1\end{array}$

(11) I have relatives who speak Spanish and I want to be able to talk to them. $\begin{array}{llll}4 & 3 & 2 & 1\end{array}$

(12) Speaking another language will help me earn lots of money when I am older. $\begin{array}{llll}4 & 3 & 2 & 1\end{array}$

(13) it will help me be accepted in my community. $\begin{array}{llll}4 & 3 & 2 & 1\end{array}$

\section{Part 3}

(1) My parents really encourage me to study Spanish.

$\begin{array}{llll}4 & 3 & 2 & 1\end{array}$

(2) My parents try to help me with my Spanish homework.

$\begin{array}{llll}4 & 3 & 2 & 1\end{array}$

(3) My parents think I should spend more time on studying Spanish.

$\begin{array}{llll}4 & 3 & 2 & 1\end{array}$

(4) My parents think I should continue to study Spanish.

$\begin{array}{llll}4 & 3 & 2 & 1\end{array}$

(5) My parents are very interested in anything that has to do with my Spanish class.

$\begin{array}{llll}4 & 3 & 2 & 1\end{array}$

How well do you think you speak Spanish? (circle one)

very well pretty well not so well poorly

How well do you think you are you doing in your Spanish class at school?

Very well pretty well not so well poorly

(1) It is important to be able to speak English and another language.

$\begin{array}{llll}4 & 3 & 2 & 1\end{array}$

(2) To live in the USA you only need to speak English

$\begin{array}{llll}4 & 3 & 2 & 1\end{array}$

(3) Knowing English plus another language can make a person more creative.

$\begin{array}{llll}4 & 3 & 2 & 1\end{array}$

(4) Speaking two languages can help to get a job.

$\begin{array}{llll}4 & 3 & 2 & 1\end{array}$

(5) It is not important to be able to write in another language.

$\begin{array}{llll}4 & 3 & 2 & 1\end{array}$

(6) Schools should just teach in English.

$\begin{array}{llll}4 & 3 & 2 & 1\end{array}$

(7) People only need to know one language.

$\begin{array}{llll}4 & 3 & 2 & 1\end{array}$ 